Literature Reviews

\title{
Socio-Economic Inequalities and their Impact on Health in Pakistan
}

\author{
Sana Sehar Vincent \\ Nursing College, Shalamar Nursing College, Pakistan
}

Article history

Received: 08-02-2016

Revised: 05-07-2016

Accepted: 13-07-2016

Email: sehar.diam@gmail.com

\begin{abstract}
This article critically reviews published literature on the relationship between socioeconomic inequalities and health outcomes in Pakistan. Studies are systematically assessed in terms to find the relationship between the social, economic, political and biological determinants to health. The studies shown that the genetical abnormalities, malnutrition and terrorism have significantly affected the quality of life. Moreover, international relations and the national policies have adversely affected the health outcome in the masses of population. Among the socio-economic determinants social exclusion and discrimination, being woman, health compliance, economic polarization in the society, education level, unemployment and work jeopardizes derives the inequality in health of the population which eventually has the implications on the poor economy of the country.
\end{abstract}

Keywords: Socio-Economic Determinants, Health Inequalities, Pakistan

\section{Introduction}

Health is an important 'consumption good' that directly contributes to an individual's 'happiness' or 'satisfaction' with no other substitute. It is also a 'capital good' in terms of assets to the nation too as well as an important component which human beings value. The environment, culture and socioeconomic strata in which people live strongly influence their chances to be healthy. Therefore, the inequality in the socioeconomic status derives the inequality in health of the population which eventually has its implications on the economic growth of the country.

Recently, WHO Commission demonstrates that health improvement can be seen as a key strategy for income growth and poverty reduction in low- and middle-income countries (Sachs, 2001). Moreover, elaborates that data from all the countries that have the significant differences in the socio-economic classes tend to have systematically higher morbidity and mortality rates among people with lower levels of education, occupation and income. European Commission shares that in longitudinal studies with socioeconomic position as an independent variable and the health outcomes as a dependent variable show that this gradient is largely due to in equal exposures of people at different positions in the social hierarchy to a variety of health risks (Mackenbach et al., 2007). Thereafter, investigating the major determinants of the
Socioeconomic Inequalities (SEIs) and their impact on the economy is the most advantageous action for the population. SEIs in health have a direct impact on the economy of the country. The larger the SEI, the greater are the magnitude of the burden of ill health and premature mortality associated with inequalities in health. Therefore, there is an intense need for the reasonable action implementation to reduce the SEI in health for the sake of productive contribution of the individuals in the economy of the country. Pakistan, a third world country needs individuals physically strong and mentally sound to bear the burden of challenges in order to meet the brutal international competitors.

\section{Materials and Methods}

The purpose of this paper is to identify the determinants of the socio-economic inequalities of health and its economic implications in Pakistan and to suggest some reasonable recommendations to reduce the impact. To compile papers on the socioeconomic inequalities and their economic implications among Pakistani nation, Cinhyl, Pubmed, Springerlink and Google Scholar were searched with the key words socioeconomic inequalities, Pakistan, health care system and economic implication from 2001 to 2015. The criterion of inclusion for choosing the articles was initially from the journals directly observing the SEIs as independent variable and economic implications as dependent variable. However, 
up to the best knowledge there is no such study in the literature, thereafter the search was expanded with the subsequent terminologies i.e., social inequalities, health bills, cultural practices, unemployment and being women. The reference list of the several review articles (Gillani et al., 2011; Sachs, 2001; Shaikh and Hatcher, 2007) was searched to identify any additional articles. Each journal article that was identified by the search was carefully examined even if SEIs was not explicitly mentioned as an indicator in the abstract. In addition to this as there is very scarce data on the SEIs therefore, local and international newspapers were also searched for the relevant information. Altogether, 23 articles were collected which matched the search and directly indicated various implications of the SEIs in Pakistani society. Unfortunately, there was very few high quality studies carried out on SEIs or adequately assessed moderating factors within this subset of studies. Still it has obtained and covered many unfolded SEIs in Pakistani populations.

\section{Findings}

\section{Biological Determinants}

Biological determinants have the indigenous role in the health of the individuals. Inheritance with the capacity and functionality of the body is the cornerstone in the effective utilization of the individual in societal roles. In Pakistani context the burden of the congenital abnormalities, malnutrition and terrorism has the great drift on the population health.

\section{Natural Abnormalities}

Gillani et al. (2011) reports that it is estimated that $2.5 \%$ of newborns, have a recognizable malformations at birth. Moreover $50 \%$ have the single malformation and the rest have the multiple malformations. Moreover Gillani et al. (2011) directed a study in Abbottabad over a period of 16 months on 2,360 patients admitted in NICU in tertiary care hospital and reports that about $10 \%$ of pediatric admissions have genetic conditions and $40 \%$ of surgical admissions are patients with congenital malformations. Furthermore, about $20-30 \%$ of infant mortality and $30-50 \%$ neonatal mortality is associated with congenital abnormalities.

\section{Malnutrition}

Pappas et al. (2008) headed a study in the 4035 government schools across the Pakistan enrolling the 203116 girls. At baseline, 23.2\% girls were stunted and $14.3 \%$ are wasted. There is a critical eye opener that in rural areas of Sindh along with $18.3 \%$ girls, $14.6 \%$ of boys were stunted too. Proponent of this, Aziz et al. (2012) conducted a cross-sectional study with multistage stratified sampling in a nationwide project of Higher Education Commission and reports the prevalence of $14 \%$ stunting among pediatric population. Alarmingly, UNICEF (2012) reports that moderate and severe stunting prevalence from 20072011 is $44 \%$ among population of Pakistan which is the emergency situation. Hence, when there is not a vertical approach in the health care delivery system, agricultural department, food and nutrition departments and foreign affairs consequently, Pakistan is producing the nation with fragile bodies and with dull brains.

\section{Terrorism}

Bhattia et al. (2011) reports that from 2002 till 2009, there were 198 suicidal terrorist events occurred in 40 districts of Pakistan. On average, from 2002 to 2006 the average was four events per year whereas; it is increases to $1350 \%$ in the years 2007 to 2009 with 58 events per year. Raja (2013) reports that Pakistanis observe 235 suicide hits, 9,257 rocket attacks and 4,256 bomb explosions in last 5 years and has lost 49,000 lives since 9/11 attacks on United Sates in different terrorist activities with a large influx of the handicap individuals. Terrorism has devastated the physical and mental health of Pakistanis' and has a shaken economy vigorously.

\section{Political Determinants}

\section{International}

The nuclear-armed nation of 180 million was considered too important to fail by the international alliance. Simultaneously, present government is just exploiting Pakistan's foreign policies related to Taliban to get the U.S. and IMF loan (Houreld, 2013). On above this International Monetary Fund is continuing to give loan to Pakistan on strict rules. Rana (2013) reports that the national debt under the present Pakistan Muslim League-Nawaz government in the last three has piled up debt to approximately Rs. 15 trillion; with the inflation rate of Rs. 6.9 is the devaluation of the rupee against the U.S., Dollar. This has flared up the poverty across the country and has tightened the living condition of the already struggling public.

\section{National}

The faulty policy and approaches of Pakistani government has places her to spends only $3.1 \%$ of its GDP on economic, social and community services with $43 \%$ on debt servicing. Only $0.8 \%$ is spent on health care (Shaikh and Hatcher, 2004). Pakistan has one of the most extended nationwide networks of public health care system with 796 hospitals, 482 RHCs, 4616 BHUs and 4144 dispensaries. Whereas, surprisingly there is the underutilization of these facilities due to many factors. Shaikh and Hatcher (2004) report that under-utilization is mainly due to restricted hours in health care facilities 
and availability of the qualified female Health Care Professional's (HCP) up to $25 \%$ in BHUs and RHCs. This explains the dearth limitation of the proper health consultation by the general poor population who pays mainly OPC.

\section{Social Determinants}

Health is grossly influenced by the social conditions and customs. Inequalities in social conditions give rise to unequal and unjust health outcomes for different social groups across the nation. In Pakistan inequalities in health bases on the ethnic groups, geographic areas gender etc., Moreover, these inequalities are not random, some strata are more socially disadvantaged groups have poorer health, greater exposure to health risks and poorer access to health services.

\section{Social Exclusion and Discrimination}

Pakistanis observes sharp division on ethnic, linguistic, sectarian basis, caste, tribes, status and occupation. Firstly, Pakistan is facing the problem of discrimination on the national level with the Baluch people. The federal's government inability and reluctance to identify and tackle the problems along with not representing the genuine interest of the people by Baluch provincial government for long period has created the major gap in socio-economic segregation of locals (BMICS, 2010). Today Baluchistan has the alarming statistics of primary school education $19.8 \%$, child labor $46.8 \%$, domestic violence $61.5 \%$, water treatment $3.5 \%$ and vaccination with the maximum coverage of polio only up to $46.1 \%$ (UNICEF, 2011). The discrimination next to insurgency in the province has led the population of 7,914,000 people forming the base of the socio-economic pyramid in Pakistan. Secondly, approximately one fourth of the Pakistani population is facing the dual disadvantageous position as being minority (Hindu and Christians) and belonging to the lower socio economic classes. They are frequently described "Achoots" or untouchables (IIDS, 2008). This provides the basis of the under privileged subgroups in the society and influence the uptake of the health services and adherence.

\section{A Life Course Perspective being Woman}

In Pakistan the segregation across the country in each ethnic group is based on the gender basis clearly. Culturally, women own the low status in the family and this prevents them from recognizing and raising their concerns about health needs (Malik and Courtney, 2011). Thereafter, women are usually deprived of the self-decision to spend money on their health and are mostly not allowed to visit a health facility alone (Shaikh and Hatcher, 2004). This dominant system of values preserves that women have to confine to their home. Thereafter, half of the population has fewer uptakes of health care services. Although the life expectancy of the women is (WB, 2012) higher than the men in Pakistan but on contrary poses the poor quality of life. Through this division, genetically more viable and dedicated people are kept apart to be economical boosters for the nation. Education of women can resolve the disparity; bring respect, social liberty and decision making authority.

\section{Health Behaviors}

Pakistan bears a high burden of communicable and chronic diseases yet alarmingly government doctor is consulted 1.2 times a year and the other health providers (other paramedics and dispensers) are visited 4.2 times a year (Shaikh and Hatcher, 2007). Government doctors' utilization is even lower in rural population as compared to urban population. Shaikh and Hatcher (2004) report that difference in language or a cultural gap of the HCP also creates a barrier of the patients in service utilization. Mostly the behavior is to delay the treatment initiation and usage of the home remedies or folk prescriptions. Whereas if the multiple symptoms develops for the longer period of time, then only health care professional were consulted.

\section{Economic Determinants}

\section{Economic Polarization in Society}

There is the vast economic polarization within the Pakistani society. Lack of social security system makes the poor more vulnerable in terms of affordability and choice of health care professionals (Shaikh and Hatcher, 2004). About $76 \%$ goes out of pocket cost in general population is a certain barrier in seeking health care. In addition to this, transportation to the health care facility and other charges spent for the treatment make the consultation more distressing (Malik and Wasay, 2011).

\section{Education}

Education of the nation is the foundation for the strong economy of the nation. Education system of Pakistan is based on unequal lines. There is a private sector, nourishing with genuine education to elite class and producing the leaders and bureaucrats. Whereas, the public sector which is providing obsolete education producing the workforce for the upper class with the little capacity to challenge the system. Memon (2007) argues that the education system of Pakistan has the shortcomings of quality, relevance and inadequate research. Surprisingly, Pakistan is ranked at 113th out of 120 registered UN members according to the research conducted by UNESCO (Takkar, 2013). There is 
enormous need to make the changes in the syllabus to develop the critical thinking rather than learn by rote the content. This prepares children to participate actively and productively in society and economy.

\section{Unemployment and Workplace Jeopardizes}

World economic outlook reports that Pakistan has the unemployment rate of $9.2 \%$. "It is documented that cumulatively terrorism has cost Pakistan around 33.02\% of its real national income i.e., terrorism costs Pakistan around $1 \%$ of real GDP per capita growth every year" (Mehmood, 2013). This has made the economy of Pakistan more permeable to poverty. The work force is facing the dual problem in the ruined economy of initially to find the job and the other is to pursue for the job according to their qualifications. Therefore the employees are forced to work in the sub-standard condition with no occupational and health safety and with less incentives. Moreover, females are the more vulnerable group as of being the easy victim of the employers' manipulations. Siegrista and Marmot (2004) highlight the evidence from epidemiological studies on associations of stressful work, as defined by high demand and low control, with cardiovascular risk and disease and other additional poor health indicators.

\section{Discussion}

In the present study, it is revealed that the biological determinants have an indigenous role in the health of the individuals. Inheritance with the capacity and functionality of the body is the cornerstone in the effective utilization of the individual in societal roles. Unfortunately, every year there were people born with congenital diseases (Gillani et al., 2011; Zaman, 2011). A possible reason for this can be the cousinage marriages, malnutrition in pregnancy and multiple pregnancies (Bhutta et al., 2009; Khor, 2003; Zaman, 2011).

In addition to this study, malnutrition among children is the most important reason for poor health among the young ones in Pakistan which is extensively discussed in the studies conducted in different areas (Baig-Ansari et al., 2006; Khuwaja et al., 2005; Shah et al., 2003). Terrorism has devastated the physical and mental health of Pakistanis' and has shaken economy drastically (Hussain, 2010; Looney, 2004; Momani, 2004), whereas these activities have not only inducted many handicaps but also alter the lifestyles of the survivors (Riedel, 2008; Shah, 2010).

International debt is a curse on Pakistan and because of this government is not having enough to spend on the basic needs of the nation (Houreld, 2013; Rais and Anwar, 2012). Additionally, many studies and surveys quote that the faulty policy and corruption in Pakistan has placed it to spend a very small proportion on health (Green et al., 2010; Javaid, 2010). Inequalities in social conditions give rise to in equal and unjustified health outcomes for different social groups across the nation. In Pakistan, inequalities in health are based on ethnicity, geographic areas and gender etc. Discrimination in Pakistan among the people is the greatest issue. In South Asia, Pakistan is a country carrying a great burden of discrimination due to many factors like religion, sects, cast, color and creed. Furthermore, gende discrimination in South Asia is a well-documented fact (Delavande and Zafar, 2013). Social exclusion is the other factor which is demolishing the health of the marginalized groups which is persistent in other studies as well (Arbaci and Malheiros, 2010; Mumtaz et al., 2012; 2011). Culturally, women are given a low status in Pakistani families and this result in poor health seeking behavior. Females in Pakistan are entitled to low social status as they do not carry the family name, cannot continue the family trade and are not expected to provide any care to their parents when they are old (Andersson et al., 2010; Qadir et al., 2011). Apart from this, unemployment is also extensively claimed to be one of the main issues behind the emerging inequalities among the masses of Pakistan. The possible reasons behind it in Pakistan are the low international financial investments in Pakistan, corruption and bad governance (Shabbir et al., 2012; Cheema and Atta, 2014).

Health inequalities have the origin in the SEIs therefore it is necessary to plan the strategies to tackle this burning issue. The recommendation comprises on the plan of action at the socio-economic status and the determinants of the inequalities which lead to the gross health of the population and have the economical results of the nation was given Fig. 1 .

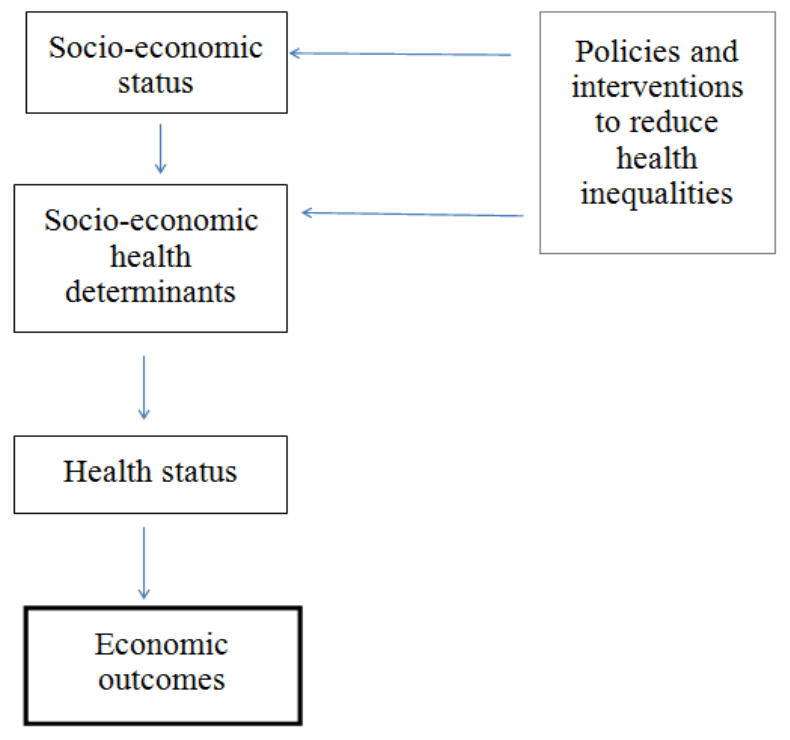

Fig. 1. Stages of intervention to address socioeconomic inequalities 
The strategy covers "upstream" measures of targeting socioeconomic disadvantage strata and "downstream" measures targeting accessibility and quality of healthcare services (Mackenbach and Stronks, 2002). The upstream included firstly the interventions and polices targeting the socioeconomic disadvantage through firstly; the international loan with the high interest rate should be avoided by the government. The legislation should take action and formulated the policies to involve in taking the debt with the consensus of the all democratic parties in the national assembly. Secondly, government should strive for the promotion of the quality education especially to those who belong to the lower socio economic classes. Thirdly, adequate taxation on the aristocrats in the society to invest the money in the antipoverty policies e.g., providing the micro finances, finding paid employments to the lower socio economic classes. "Downstream" measures usually target accessibility and quality of healthcare services and there should be the formation of vertical health care system to provide the integrated health care delivery. Moreover health education should be more emphasized.

\section{Strengths and Limitations of the Study}

The strength of this study is that it is the first literature review in the Pakistan on the topic. Moreover, this study has gathered rich data on the biological, political, social and economical determinants of inequalities affecting the masses in Pakistan.

The major limitation of this study is that there unfortunately, there were too few high quality studies that reported the concept of the SEIs in Pakistani context. Moreover, there were no such studies which give the direct association of different factors of the SEIs on the economy of the country.

\section{Implications for Research and Policy}

SEIs in health have the direct impact on the economy of the country. The larger the SEIs, the greater are the magnitude of the burden of ill health and premature mortalities. Therefore there is the intense need for the reasonable action implementation to reduce the SEI in health for the sake of productive contribution of the individuals in the economy of the country. Pakistan, the third world country needs physically strong and mentally sound individuals to bear the burden of challenges in the brutal international competitors. This review has confirmed that there are relationship between SEIs and poor health of the individuals. For the future researchers this research will provide a base to for the hypothesis formulation and testing the correlation of different variables of SEIs.

\section{Conclusion}

Health is mainly significantly affected by the socioeconomic status of the division in the society and on the abilities to generate wealth. Government of Pakistan need to have the stringent formulation of the policies with the effective implementation to break the wishers cycle of the lower socio-economic division effecting with poor health are driven to be less weight age in the economy and remain poor. The synergic efforts by the public and private health care system are needed in achieving the greater accountability, transparency and efficiency. Reduction in the socioeconomic inequality and equity in health care systems is the key to economical success of Pakistan!

\section{Acknowledgement}

I want to thank Dr. Tazeen Sayed Ali (Associate Professor, School of Nursing, The Aga Khan University) for guidance with the topic of such a great impact. I also like to show my gratitude to the Ms. Neelofer Khan (Assistant Professor, University of Health Sciences) for sharing her expertise in languag during the course of research. In addition to this, thanks to all the "anonymous" reviewers of "International Journal of Nursing Research" for their constructive feedback. Moreover, any errors is our own and should not tarnish the reputations of these esteemed persons.

\section{Funding Information}

This is a stand-alone literature review; hence no funding agency provided support to conduct research, preparation of the article or submission of the work.

\section{Ethical Concerns}

Following ethical concerns were considered during the literature review:

- This is a stand-alone literature review hence authorship is limited to the primary author

- Article is completely original work and other's work has been appropriately cited or quoted. Moreover, it was made sure reports of original research should present an accurate account of the work performed

- This article is not submitted $r$ published in the form of an abstract; publication as an academic thesis; publication as an electronic preprint

- All the researches included reported the data in the aggregate form to maintain the anonymity of the participants in the review 


\section{References}

Andersson, N., A. Cockcroft, U. Ansari, K. Omer and N.M. Ansari et al., 2010. Barriers to disclosing and reporting violence among women in Pakistan: Findings from a national household survey and focus group discussions. J. Interpersonal Violence, 25: $1965-1985$.

DOI: $10.1177 / 0886260509354512$

Arbaci, S. and J. Malheiros, 2010. De-segregation, peripheralisation and the social exclusion of immigrants: Southern European cities in the 1990s. J. Ethnic Migrat. Stud., 36: 227-255. DOI: $10.1080 / 13691830903387378$

Aziz, S., W. Noor-ul-Ain, R. Majeed, I. Qayum and I. Ahmed et al., 2012. Growth centile charts (anthropometric measurement) of Pakistani pediatric population. J. Pak. Med. Assoc., 62: 367-377. PMID: 22755283

Baig-Ansari, N., M.H. Rahbar, Z.A. Bhutta and S.H. Badruddin, 2006. Child's gender and household food insecurity are associated with stunting among young Pakistani children residing in urban squatter settlements. Food Nutr. Bull., 27: 114-127.

DOI: $10.1177 / 156482650602700203$

BMICS, 2010. Planning and development. Balochistan Multiple Indicator Cluster Survey, Department Government of Balochistan.

Bhattia, J.A., A. Mehmood, M. Shahidb, S.A. Bhattia and U. Akhtarc et al., 2011. Epidemiological patterns of suicide terrorism in the civilian Pakistani population. Int. J. Injury Control Safety Promot., 18: 205-211. PMID: 21462019

Bhutta, Z.A., A. Rizvi, F. Raza, S. Hotwani and S. Zaidi et al., 2009. A comparative evaluation of multiple micronutrient and iron-folic acid supplementation during pregnancy in Pakistan: Impact on pregnancy outcomes. Food Nutrit. Bull., 30: S496-S505.

DOI: $10.1177 / 15648265090304 \mathrm{~S} 404$

Cheema, A.R. and A. Atta, 2014. Economic determinants of unemployment in Pakistan: Co-integration analysis. Int. J. Bus. Soc. Sci., 5: 209-221.

Delavande, A. and B. Zafar, 2013. Gender discrimination and social identity: Experimental evidence from urban Pakistan. FRB New York Staff Report. DOI: 10.2139/ssrn.2198386

Gillani, S., N.H.S. Kazmi, S. Najeeb, S. Hussain and A. Raza, 2011. Frequencies of congenital anomalies among newborns admitted in nursery of Ayub Teaching Hospital Abbottabad, Pakistan. J. Ayub Med. Coll. Abbottabad, 23: 117-121. PMID: 22830164

Green, D., R. King and M. Miller-Dawkins, 2010. The global economic crisis and developing countries. Oxfam Policy Pract.: Agric. Food Land, 10: 67-138.
Houreld, K., 2013. IMF team visits Pakistan to kick the tires on economic reforms.

Hussain, S.E., 2010. Terrorism in Pakistan: Incident patterns, terrorists' characteristics and the impact of terrorist arrests on terrorism.

Javaid, U., 2010. Corruption and its deep impact on good governance in Pakistan. Pak. Econom. Soc. Rev., 48: $123-134$. DOI: $10.2307 / 41762417$

Khor, G.L., 2003. Update on the prevalence of malnutrition among children in Asia. Nepal Med. Coll. J., 5: 113-122. PMID: 15024783

Khuwaja, S., B.J. Selwyn and S.M. Shah, 2005. Prevalence and correlates of stunting among primary school children in rural areas of southern Pakistan. J. Tropical Pediatr., 51: 72-77. DOI: $10.1093 /$ tropej/fmh067

WB, 2012. Life expectancy at birth, female (years). World Bank.

IIDS, 2008. Long behind schedule: A study on the plight of shedule caste Hindus in Pakistan. Indian Instituite of Dalit Studies.

Looney, R., 2004. Failed economic take-offs and terrorism in Pakistan: Conceptualizing a proper role for U.S. assistance. Asian Survey, 44: 771-793. DOI: 10.1525/as.2004.44.6.771

Mackenbach, J.P. and K. Stronks, 2002. A strategy for tackling health inequalities in the Netherlands. Brit. Med. J., 325: 1029-1033.

DOI: $10.1136 / \mathrm{bmj} .325 .7371 .1029$

Mackenbach, J., W.J. Meerding and A. Kunst, 2007. Economic implications of socio-economic inequalities in health in the European Union. European Commision, Netherlands.

Malik, M.A. and M. Wasay, 2011. Economics of health and health care in Pakistan. J. Pak. Med. Assoc., 63: 814-815.

Malik, S. and K. Courtney, 2011. Higher education and women's empowerment in Pakistan. Gender Educ., 23: 29-45.

DOI: $10.1080 / 09540251003674071$

Mehmood, S., 2013. Terrorism and the macroeconomy: Evidence from Pakistan.

Memon, G.R., 2007. Education in Pakistan: The key issues, problems and the new challenges. J. Manage. Soc. Sci., 3: 47-55.

Momani, B., 2004. The IMF, the U.S. war on terrorism and Pakistan. Asian Affairs: Am. Rev., 31: 41-51. DOI: 10.3200/AAFS.31.1.41-51

Mumtaz, Z., B. O'Brien, A. Bhatti and G.S. Jhangri, 2012. Are community midwives addressing the inequities in access to skilled birth attendance in Punjab, Pakistan? Gender, class and social exclusion. BMC Health Services Res., 12: 326-326. DOI: $10.1186 / 1472-6963-12-326$ 
Mumtaz, Z., S. Salway, L. Shanner, A. Bhatti and L. Laing, 2011. Maternal deaths in Pakistan: Intersection of gender, caste and social exclusion. BMC Int. Health Hum. Rights, 11: S4-S4. DOI: $10.1186 / 1472-698 X-11-S 2-S 4$

Pappas, G., A. Agha, G. Rafique, K. Khan and S. Badruddin et al., 2008. Community-based approaches to combating malnutrition and poor education among girls in resource-poor settings: Report of a large scale intervention in Pakistan. Rural. Remote. Health, 8: 820-820. PMID: 18785799

Qadir, F., M.M. Khan, G. Medhin and M. Prince, 2011. Male gender preference, female gender disadvantage as risk factors for psychological morbidity in Pakistani women of childbearing age-a life course perspective. BMC Public Health, 11: 745-745.

DOI: $10.1186 / 1471-2458-11-745$

Rais, S.I. and T. Anwar, 2012. Public debt and economic growth in Pakistan: A time series analysis from 1972 to 2010. Acad. Res. Int., 2: 535-544.

Raja, M., 2013. Pakistani victims: War on terror toll put at 49,000. The Express Tribune.

Rana, S., 2013. Rising debt: Govt adds a trillion in three months. The Express Tribune.

Riedel, B., 2008. Pakistan and terror: The eye of the storm. Ann. Am. Acad. Political Soc. Sci., 618: 31-45. DOI: $10.1177 / 0002716208316746$

Sachs, J.D., 2001. Macroeconomics and Health: Investing in Health for Economic Development. 1st Edn., World Health Organization, Geneva, ISBN-10: 924154550X, pp: 202.

Shabbir, G., S. Anwar, Z. Hussain and M. Imran, 2012. Contribution of financial sector development in reducing unemployment in Pakistan. Int. J. Econom. Fin., 4: 260-268. DOI: 10.5539/ijef.v4n1p260
Shah, S.A., 2010. War on terrorism: Self defense, operation enduring freedom and the legality of U.S. drone attacks in Pakistan. Was. Univ. Global Stud. Law Rev., 9: 77-129.

Shah, S.M., B.J. Selwyn, S. Luby, A. Merchant and R. Bano, 2003. Prevalence and correlates of stunting among children in rural Pakistan. Pediatr. Int., 45: 49-53. DOI: 10.1046/j.1442-200X.2003.01652.x

Shaikh, B.T. and J. Hatcher, 2004. Health seeking behaviour and health service utilization in Pakistan: Challenging the policy makers. J. Public Health, 27: 49-54. DOI: 10.1093/pubmed/fdh207

Shaikh, B.T. and J. Hatcher, 2007. Health seeking behaviour and health services utilization trends in National Health Survey of Pakistan: What needs to be done? J. Pak. Med. Assoc., 57: 411-414. PMID: 17902526

Siegrista, J. and M. Marmot, 2004. Health inequalities and the psychosocial environment-two scientific challenges. Soc. Sci. Med., 58: 1463-1473.

DOI: $10.1016 / \mathrm{S} 0277-9536(03) 00349-6$

Takkar, I., 2013. Street Children. Dawn.

UNICEF, 2012. Pakistan statistics.

Zaman, M., 2011. Exchange Marriages in South Punjab, Pakistan: A Sociological Analysis of Kinship Structure, Agency and Symbolic Culture. 1st Edn., Peter Lang, Frankfurt am Main, ISBN-10: 3631635303, pp: 202. 